\title{
ALIGNING TAX INCENTIVES WITH MOTIVATIONS FOR PHILANTHROPY
}

\section{Insights from psychology and neuroscience}

\author{
Jo Cutler
}

\section{Introduction}

Tax incentives for philanthropy aim to increase the positive impacts of charitable activities, in some cases by promoting individual donations. There are many conceivable types of tax incentive to achieve this, and they differ in important ways. A vital component in determining the efficacy of each is the extent to which tax incentives increase the likelihood and size of philanthropic donations. Research addressing these questions has traditionally been concentrated within the fields of economics and public policy. However, alongside this progress, much work has been conducted in psychology and neuroscience to understand motivations for prosocial behaviour - actions to help other people - generally, and charitable giving specifically. There is also increasing recognition that psychological concepts, for example, wellbeing and happiness, may be critical in promoting philanthropy (Sellen 2021) and that the efficiency of government incentives cannot be quantified without taking into account citizens' responses to those incentives (Steinberg 2021). Research has also identified different responses to functionally equivalent subsidies (Eckel and Grossman 2003) and differences between individuals' responses to tax incentives (Lideikyte Huber 2020). These findings suggest that factors other than objective economic value are important for understanding philanthropy and the role of tax incentives. Here, I provide a review of the literature from psychology and neuroscience, tailored to be applicable to tax incentives and with a focus on gifts of money made by individuals. Only by understanding why people are philanthropic can the alignment of tax incentives with these motivations be assessed.

Studies on charitable giving in psychology and neuroscience constitute a subsection of research on prosocial decision-making, a specific application of research on decision-making generally. At this most general level, research identifies the costs and benefits associated with the different choice options and how these are integrated in value calculations in order to make a decision (Croxson et al. 2009). Value can be defined as the importance, worth, or usefulness of something and the process of estimating this. The idea of subjective value differentiates experienced desirability from objective worth (Peters and Büchel 2010). For example, the value of food changes depending on how much one has already eaten. In the context of philanthropy, choosing to donate suggests the total subjective value of this option is greater than the value of 
not donating. A comprehensive review of the literature on charitable giving identified psychological benefits as well as overall costs and benefits as some of the key mechanisms that drive giving (Bekkers and Wiepking 2010). As charitable giving is defined by giving away money, the subjective benefits must outweigh these costs.

From this perspective, tax incentives that aim to increase the frequency or levels of philanthropic giving must increase the subjective benefits or decrease the (subjective) costs of donating. These incentives will be efficient if they promote an increase in giving that is greater than the objective cost of the incentive to the government. The psychological or subjective benefits of philanthropic decisions can also be conceptualised as motivations for philanthropy and can be classified in different ways. In reality, it is likely that multiple motivations work together, even within a single decision. However, separating different motivations is necessary to understand and assess the possible motivations. Psychology and neuroscience can offer insight into different motivations for giving, how these can be increased or decreased, and how they may differ between individuals. Before outlining two distinctions between motivations for philanthropy that relate to tax incentives, I first give an overview of the methods used in the relevant psychology and neuroscience research.

\section{Methods from psychology and neuroscience}

\section{Behavioural experiments}

Perhaps the most obvious way to evaluate motivations for philanthropy is to ask people why they give. This can be done through questionnaires or scales quantifying different motivations (Konrath and Handy 2018) or qualitative interviews (Breeze 2013). While these approaches provide detailed information about donors' understanding of their own motivations, they cannot provide the experimental manipulations of motivations that are required to conclude a causal effect on giving. Behavioural experiments that provide these manipulations therefore offer a complementary approach to self-report and interview methods.

A large body of literature in experimental psychology and behavioural economics measures participants' decisions to give away or keep money in different contexts. Many of these studies use economic games such as the dictator game, ultimatum game, trust game, or public goods game. The dictator game is the most relevant to many forms of charitable giving. Participants in these studies are endowed with a certain amount of money and have the opportunity to give some or all of it away (Kahneman et al. 1986). The recipient can be another person or a charity. In the ultimatum game, the participant again receives an amount of money and has to decide whether to give some away, but now the recipient can decide whether to accept the offer or reject it, leaving both them and the participant who made the offer with nothing (Güth et al. 1982). Participants in the trust game endowed with money must decide what amount, if any, to 'invest' in another person. The recipient then receives the invested amount multiplied, for example, tripled, and has the opportunity to repay the participant by returning some of this amount (Berg et al. 1995). The ultimatum and trust games are used to study prosocial behaviours motivated by fairness, equity, and reciprocity, as well as responses to violations of these principles. Finally, the public goods game approximates contributions to a cause that the donor also benefits from. Groups of participants all receive an endowment and decide how much to contribute into a group fund or 'pot'. This amount is often multiplied, for example, by 1.25, to incentivise contributions, then equally divided between all group members, regardless of contribution (Rapoport and Chammah 1965). The greatest public good is therefore achieved by all participants contributing the full amount, but the greatest individual gain results from 
keeping one's own money and 'free riding' on others' contributions. These games all measure decisions to give money away, but by introducing different potential benefits, they create different motivations.

Within these economic games, additional manipulations can be introduced to measure whether they increase or decrease giving. For example, in a dictator game, participants gave more to a charity when they saw a photo of a child in need (Genevsky et al. 2013). Other studies have adapted the dictator game to ask how much money participants are willing to give to prevent another person experiencing pain (FeldmanHall et al. 2012) and show greater motivation to prevent the pain of someone else than oneself (Crockett et al. 2014). Evidence that these emotional factors promote donations, and link to participants' personality traits, suggests a role for psychological mechanisms such as empathy in some forms of giving (FeldmanHall et al. 2015).

Measuring decisions to give money away directly can be informative, given the reasonable assumption that choices generally reflect the option with the highest value (Rangel et al. 2008). However, an issue with just measuring donation decisions in experiments is that they can be biased if participants act in a socially desirable way, which does not reflect their true motivations (Fernandes and Randall 1992). Behavioural experiments are not limited to measuring decisions whether to donate. For example, an alternative to measuring willingness to pay (donations) is willingness to put in physical effort to earn money for other people (Lockwood et al. 2017). If a source of subjective value during philanthropy is creating positive outcomes for other people, prosocial behaviours that cause such positive outcomes will be experienced as 'rewarding', and donors are more likely to repeat them (Gęsiarz and Crockett 2015). Another alternative to measuring donation decisions is therefore a behavioural measure of whether people learn to repeat actions that benefit others (Lockwood et al. 2016; Cutler et al. 2021).

\section{Neuroimaging}

While there are many ways to measure behaviours relevant for prosociality and philanthropy, a focus on behaviour may miss the fact that similar behaviours can be motivated by a wide range of factors. The differences between motivations are crucial to understand, predict, and encourage prosocial behaviours (Hein et al. 2016). Neuroimaging tools can offer additional insights. The method from neuroimaging most used in studies relevant to philanthropy is magnetic resonance imaging (MRI). In these studies, participants lie inside a large tube containing powerful magnets and coils that transmit and receive pulses of radio waves. These can create images of the structure of the brain (or any part of the body for medical tests), as different tissues have different properties and generate distinct signals. For research on philanthropy, we are mostly interested in collecting functional MRI (fMRI) datasets that measure activity in different areas of the brain during an experimental task. Participants lying in the scanner can complete an experimental task by viewing a screen at the end of the tube via a mirror and pressing buttons to make responses or choices. During the task, the brain is scanned many times, approximately every two seconds. These data can provide information about brain activity due to the fact that blood full of oxygen has a different signal in the scanner to blood that is low in oxygen. When areas of the brain are active, they receive an increased supply of oxygenated blood. In analysis, we then match up these changes in signal that represent increased blood flow, and thus brain activity, to what was happening in the experimental task at the time.

The most common way of using AMRI in existing research on prosocial behaviour is to compare different conditions, often using one of the economic games described previously, and look for similarities and differences in regions of activity. For example, in several studies, participants 
decided whether to donate to charities and also received money for themselves during an fMRI scan. Results suggest that some areas may be involved in both giving away and receiving money (Moll et al. 2006; Harbaugh et al. 2007; Genevsky et al. 2013). Similarly, some regions of the brain were involved in both learning about actions that benefit ourselves and learning about actions that benefit other people. However, there were also differences between these types of learning (Lockwood et al. 2016). These findings offer insight into how the subjective benefits of giving may be calculated and represented in the brain, overlapping with networks involved in representing benefits for ourselves but also unique. In the following, I outline results on how these patterns of brain activity differ when financial incentives for giving introduce different motivations.

\section{Motivations for philanthropy}

To date, few studies have applied techniques from experimental psychology (Eckel and Grossman 2003, 2006; Davis et al. 2005; Peng and Liu 2020; Ugazio et al. 2021; see Adena 2021 for a review of field experiments), and to my knowledge no studies have applied neuroimaging methods, to the question of tax incentives in philanthropy. However, there is a large and rich literature in these disciplines on different motivations for giving. Here I outline two distinctions between altruistic and strategic giving and between action-oriented and outcome-oriented giving - that are particularly relevant, as they align with different categories of tax incentive.

\section{Altruistic or strategic giving?}

Philanthropy could be considered a challenge for traditional theories in economics that suggest humans or Homo economicus are self interested (Adamus 2017). One possibility is that prosocial behaviours can lead to extrinsic - tangible, often financial - benefits for the donor as well as the recipient. A possible motivation for prosocial behaviour is therefore to strategically gain such rewards. However, people are also prosocial in contexts where this is not the case (Charities Aid Foundation 2019). I will describe these choices, to be generous when there is no opportunity to gain extrinsic rewards, as altruistic. This broad distinction between altruistic and strategic motivations aligns with several of the eight drivers for charitable giving identified in a review, particularly psychological benefits and 'altruism', as defined by the authors, compared to material costs and benefits (Bekkers and Wiepking 2010).

If altruistic choices to give are generous acts with no opportunity to gain extrinsic rewards, motivations for giving in these contexts rely on intrinsic rewards. Sources of intrinsic reward include 'warm glow' (Andreoni 1989, 1990), vicarious reward experience (Mobbs et al. 2009), relief of empathic concern (FeldmanHall et al. 2015), and self-enhancement from adherence to moral codes or social norms (Niemi et al. 2018). Intrinsic incentives to give are often studied through donations to charities, payments to prevent others from coming to harm (FeldmanHall et al. 2012), or dictator games (Kahneman et al. 1986). A meta-analysis of 616 dictator game treatments from 131 papers showed that on average, participants gave $28.35 \%$ of the total amount. Of the 328 treatments with full range information available, $16.74 \%$ of participants gave half of the total, and $5.44 \%$ gave away everything (Engel 2011). These results, combined with the extent of charitable giving in the real world, provide evidence of altruistic giving.

In contrast, strategic choices to give are generous acts that can also lead to extrinsic reward, which is thought to be the dominant factor in the decision process (Frey and Oberholzer-Gee 1997). Experimental tasks that measure strategic prosocial behaviour include the ultimatum game, trust game, and public goods game in which generosity can also benefit the donor through 
cooperation or reciprocity. For example, participants may contribute to the group pot or public good, as it leads to positive outcomes for the other group members and themselves. Interestingly, anonymous charitable donations are often considered a prototypical example of altruistic behaviour. However, there many examples of strategic benefits for philanthropy. Donations to some causes may be better characterised as providing a public good if the donor is among the beneficiaries. Membership schemes run by charitable organisations could be motivated by obtaining membership benefits, rather than donating for altruistic reasons. Such opportunities for strategic benefits may increase with the value of the gift and include indirect extrinsic benefits, for example, corporate philanthropy ultimately improving sales.

Crucially, some tax incentives create strategic benefits from charitable giving. Two of the most common tax incentives for philanthropy are matching grants and tax rebates (tax deductions or credits). A key distinction between these is whether the money contributed through the tax incentive goes to the charity or to the donor, respectively. This distinction in the way tax incentives are implemented aligns with the distinction between altruistic and strategic motivations for philanthropy. For matching grants to be effective, the donor must value benefits for the charity (altruistic motivation), whereas tax rebates create a strategic motivation for giving.

Situations and tax incentives that create opportunities for strategic motivations do not exclude the possibility that altruistic motivations also play a role (Capraro and Rand 2017). In other words, a donor could make donations through a scheme that offers tax rebates without taking into account the fact they will benefit financially from doing so. It is difficult to design experiments that exclude altruistic motivations. This is similar to the difficulty with separating whether someone does their job to earn money or because they enjoy it; we can test whether they would do the work for free, but it is difficult to manipulate levels of intrinsic motivation. If donors are giving for altruistic reasons and not considering tax rebates, the subsidy is at best irrelevant and wasteful and at worst conflicts with or 'crowds out' the altruistic motivations (Frey and Oberholzer-Gee 1997). However, there is evidence that strategic motivations do play a role in prosocial behaviour, as manipulations to increase the size or likelihood of the extrinsic rewards increase levels of prosocial behaviour (Camerer 2003; Camerer and Fehr 2003). A comparison of contexts where extrinsic rewards are possible with those where they are not can help identify how these motivations are different.

To understand the differences between altruistic and strategic prosocial decisions, we conducted a meta-analysis to summarise over a decade of fMRI studies on this topic, combining data from over 1000 participants (Cutler and Campbell-Meiklejohn 2019). We classified studies into an altruistic group and strategic group based on whether the experimental task meant that participants could gain extrinsic benefits, money for themselves, through being prosocial or whether the only reasons to give were altruistic.

Importantly, in this study, all charitable giving tasks were included in the altruistic decisions group, as no studies have used fMRI to look at financial incentives for the donor during charitable giving. However, looking at other types of decision which have both extrinsic and intrinsic benefits can help us understand how these motivations interact in the decision process.

Results showed that giving to others, compared to being selfish, in both altruistic and strategic contexts was associated with overlapping increases in activity across several areas of the brain. A common way of interpreting results from fMRI studies is to look at what other types of task or stimuli are associated with activity in these areas. The areas that were active during both types of generosity included the nucleus accumbens ( $\mathrm{NuAcc}$ ), ventromedial prefrontal cortex (vmPFC), orbitofrontal cortex (OFC), anterior cingulate cortex (ACC), and subgenual area of the ACC (sgACC). These are considered key elements of the reward and value-computation networks (Bartra et al. 2013). The sgACC has also been linked to charitable donations specifically (Moll et al. 
2006), distinguishes altruism from decisions which benefit the individual (Pulcu et al. 2014), and signals learning which actions help others (Lockwood et al. 2016). Activity in the sgACC is also linked to a reduced propensity to harm others in utilitarian judgements (Wiech et al. 2013), as well as emotional processing in social contexts (Drevets et al. 2008). However, it is important to note we cannot conclude that sgACC activity during generosity necessarily means emotional processing, or any other previously identified process, was taking place during decisions to give money. The conclusions are broader: overlap in the brain between altruistic and strategic giving suggests commonalities in how intrinsic and extrinsic rewards are represented (Levy and Glimcher 2012).

We also compared activity between the two groups of studies and found key differences between altruistic and strategic choices to give. Altruistic choices to give correlated with greater activation than strategic choices in several regions. That any regions show greater activity during altruistic choices suggests there is something unique about decisions to give money away with no expectation of something in return. Of the areas of the brain involved in both types of giving, the one that showed even greater activity during strategic decisions was the right NuAcc. Activity in this region has been associated with multiple types of reward (Levy and Glimcher 2012), including money, intrinsic reward (Moll et al. 2006; Harbaugh et al. 2007; Genevsky et al. 2013), and social cooperation (Rilling et al. 2002). The issues of interpretation apply here too, but this finding could show the neural basis of how intrinsic and extrinsic benefits are combined during strategic decisions to give. The fact that activity in this area was highest during strategic decisions could fit with behavioural findings that people are more likely to be generous when they can get something in return (Zheng and Zhu 2013).

In summary, tax incentives following individual donations can be divided based on whether the benefit is to the philanthropic organisation or the donor. Incentives such as matching donations benefit organisations by increasing the overall value of gifts. For donors to value these incentives requires altruistic motivations. In contrast, making donations tax deductible provides financial incentives to individuals. Tax incentives for social enterprises may also provide benefits to the individual customer, as they obtain a desirable product while promoting social welfare. These situations with positive material benefits for both the benefactor and beneficiary mean generosity can be strategic rather than altruistic. Differences between patterns of brain activity during altruistic and strategic choices make a clear case that decisions in these two contexts rely on different processes and should not be considered interchangeable.

Our finding that some regions were most active during strategic decisions could suggest that contexts which benefit both the benefactor and beneficiary are the most desirable. However, there is evidence that altruistic behaviour can decrease following the introduction of extrinsic incentives (Frey and Oberholzer-Gee 1997). In the analogy of working to earn money or because of intrinsic motivation, this is like introducing payment for tasks someone is already doing just because they want to. Imagine someone who loves painting in their spare time being offered a small payment in return. It risks changing how the value of the activity is calculated and potentially undermining intrinsic motivations. Our results could show the neural basis of such 'crowding out' of altruistic motivations by selfish ones if these different motivations represented are within the same neural circuits. We also found other regions more involved during altruistic decisions, suggesting something unique about choices to help others with no opportunity for financial gain. In other words, introducing extrinsic incentives in an attempt to increase generosity could change the core motivations behind giving.

While the results of our meta-analysis and each of the individual studies on this topic provide insight into how the brain calculates the costs and benefits of giving, more work is needed to apply these ideas to tax incentives specifically. One key question for future research is whether 
tax incentives that offer money to the donor do alter, undermine, or increase their altruistic motivations. Perhaps there are contexts in which donors perceive them as reducing the cost of a donation and so increase the amount they donate. One interesting approach to this question could be to measure the impact of introducing tax incentives that benefit the donor in philanthropic contexts that differ in whether an extrinsic benefit is already available. For example, if tax deductions successfully increase donations through membership schemes but have a less positive impact on donations without an existing extrinsic benefit, considering the original motivations strategic or altruistic offers a possible interpretation.

As with much research in psychology and neuroscience, an important limitation is the artificial nature of experimental tasks, particularly those completed while lying in an MRI scanner. Examples of real-world tax incentives are often more complex than the distinction between altruistic and strategic motivations. UK gift aid applied to the basic rate of tax would align with altruistic motivations, as the charity claims $25 \%$ extra on donations. For donors to value this requires them to value the charity gaining more money from their gift. However, higherrate taxpayers can personally claim back a tax deduction, creating an additional extrinsic benefit from their giving. Another more complex example is interacting tax rules, for example, appreciated property rules or donations of shares that have changed in value. In addition to complexities in the financial value of tax incentives for the donor, potential benefits of giving may not fall neatly into an intrinsic or extrinsic category. For example, donations to organisations that promote donor's political or cultural beliefs could be seen as strategically motivated to achieve the donor's aims, but these outcomes are less tangible than financial benefits. It may be possible to utilise the complex nature of real-world tax incentives, such as differences between individuals or countries, to design field experiments or observational studies on this topic. For example, donations that straddle tax rate or tax credit rate changes could offer interesting opportunities to study strategic motivations. While these situations offer natural examples of increased extrinsic rewards and opportunities for strategic motivation, it is important to reiterate that donors may still be giving for altruistic reasons.

\section{Action or outcome-oriented altruism?}

The findings outlined previously suggest that while giving can be strategic, there is also an intrinsic value to giving money away, which provides altruistic motivations for philanthropy. This raises the question: why are people altruistic? Previous work suggests a key distinction between motivations for altruism: pure and impure (Andreoni 1989, 1990), more recently also termed outcome-oriented and action-oriented altruism, respectively (Kuss et al. 2013). Pure or outcome-oriented altruism is motivated by the positive outcome for others or public good, independent of one's own contribution. In contrast, action-oriented altruism is motivated by positive emotions from the act of giving. This was originally described as warm-glow giving (Andreoni 1989, 1990), but recent uses of the term 'warm glow' do not necessarily exclude outcome-orientations (Västfjäll et al. 2015; Erlandsson et al. 2016; O’Brien and Kassirer 2019) so I use the terms action- and outcome-oriented altruism here.

As action-oriented altruism depends on the act of giving, it could be argued that a key component is feeling personally responsible for having a positive impact. In contrast, if someone is outcome oriented, they should see value in positive outcomes for others that they were not responsible for. This distinction in the role of personal responsibility links to the question of how effective it is to spend taxes on incentives to promote individuals' donations, compared to those that do not involve individuals. Examples of tax incentives that do not involve individuals are tax exemptions or special status granted to philanthropic organisations. More broadly, taxes 
can be spent directly on public policy goals that increase social welfare, rather than on any form of tax incentive. If people's motivations align with outcome-oriented altruism and so focus on the positive outcomes for philanthropic organisations and their causes, public support for these different ways of spending tax will be similar, to the extent they have equal social impacts. However, as these incentives remove individuals' agency, in order for them to align with motivations, people must value positive outcomes for others even when they do not feel personally responsible for the outcome. If personal responsibility plays a key role in motivating altruism, only tax incentives that involve individuals and make them feel their actions have a positive impact will be popular, but these will have the potential to increase donations.

Research in economics, psychology, and neuroscience provides evidence for both actionand outcome-oriented motivations for altruism. As outcome-oriented altruism is motivated by the benefit for the other person, separate from the act of helping, it can be difficult to measure based on behaviour alone. One prediction of outcome-oriented motivations is that donations by oneself and donations by others are perfect substitutes for each other if they create the same impact for the recipient(s). This means that if someone else contributes to a cause, an outcomeoriented donor should decrease their contribution by that amount. This is known as complete 'crowding out' (Ottoni-Wilhelm et al. 2017), but, importantly, this form of crowding out is distinct from the motivational crowding out described previously, when extrinsic incentives for prosocial behaviour undermine intrinsic ones. Experimental tests of crowding out have generally not shown support for outcome orientation (Andreoni 1990), and a review of crowding out in response to government support found mixed and context-dependent results (Wit and Bekkers 2017). However, an issue with experimental paradigms is that anything less than complete crowding out is considered evidence against outcome orientation, so the power to detect it is low. Another issue is that predictions of complete crowding out are specific to contexts where additional donations will not increase the size or strength of the positive outcome, and these are very unlikely in the real world.

Action-oriented altruism, motivated by the reward of personally having a positive impact on another person or cause, was introduced to explain the lack of complete crowding out found in behavioural economics experiments (Andreoni 1989, 1990). A similar pattern of behaviour is if donors fail to consider the marginal benefit of their gift, for example, donating to an appeal that has already raised enough to meet its aims rather than one that has not yet reached its target. Anecdotal and scientific evidence support the idea that many altruistic behaviours are not those that would bring about the greatest possible impact. In the charitable giving domain, for example, most donors do not choose causes or organisations based on the efficiency of their impact (Van Iwaarden et al. 2009). It is common to choose organisations based on the percentage they spend on projects (Caviola et al. 2014), and a lack of overhead costs promotes giving (Gneezy et al. 2014), even though this measure is often meaningless for comparing efficiency (Bowman 2006). Many other factors also lead to biases in altruistic behaviour, as they diverge from the common view that all lives have equal value (Slovic et al. 2011). These biases include preferring to help certain recipients over others (Everett et al. 2015) and the nonlinear relationships between the number of people in need and responses (Dickert et al. 2012). Warm-glow motivations within charities themselves have also been linked to inefficiency (Scharf 2014). If action-oriented motivations apply for responses to tax incentives for philanthropy, donors will respond to those that make them feel best about their own impact, even at the expense of objective impact for the beneficiaries or public good.

Using fMRI, work on observing others' gain, not because of altruism or prosocial behaviour, has identified the neural mechanisms of vicarious reward during positive outcomes for 
others one is not responsible for. Like donating to charity and receiving money for oneself, seeing others receive money was associated with activity in areas including NuAcc (Mobbs et al. 2009). This vicarious reward was powerful enough to drive learning, although learning rates were slower than for the self (Lockwood et al. 2016). A similar study measured activity in $\mathrm{NuAcc}$ during gains for the participant, a charity, and both the participant and a charity. The extent of activity in NuAcc when just the charity gained money correlated with how much the participant enjoyed winning for the charity (Spaans et al. 2018). While these results combined suggest that positive outcomes for others and charities have value, they do not consider costly prosocial behaviours to achieve these positive outcomes.

Several studies have developed measures of both outcome and action orientations using fMRI. In the first, participants made voluntary charitable donations and also observed taxlike involuntary transfers from their money to the charity. The NuAcc was active in both contexts, which the authors conclude shows participants did find the tax-like transfers rewarding. This region showed even more activity during voluntary donations, supporting the existence of both outcome-oriented and action-oriented giving (Harbaugh et al. 2007). In a different paradigm, participants also made costly charitable donation decisions in the scanner but on some trials, donations were discarded. As the action-oriented reward of being generous is unaffected by whether a donation is discarded, signals in the NuAcc on discarded donations were considered evidence for other-oriented motivations. This was present, but only for the most generous participants (Kuss et al. 2013), again supporting a relationship between outcome orientation and giving. In other words, most participants did not seem to care whether their donations actually reached the charity. Such differences between people suggest differences in motivations for altruism. These may also link to findings in the literature on tax and philanthropy of differences in how responsive people are to incentives. Understanding how incentives align with motivations may help explain these differences, and in future, if incentives were more aligned with individuals' motivations, it may boost their efficacy.

In summary, research using fMRI and building on theories from economics provides some evidence for pure or outcome-oriented altruistic motivation. Such motivation would align with support for directing taxes towards social welfare policies or tax exemption for charities to minimise outgoings. However, this was often only found in the most generous participants. For other people, being responsible for donations was crucial, in line with action-oriented altruistic motivation or warm-glow giving. This suggests people may prefer incentives that increase their feeling of responsibility for helping others. As with the section on altruistic and strategic giving, further research is needed to test these ideas and extend them to tax incentives specifically, especially including the complexities of real-world schemes. For example, matching grants could be perceived as the result of multiple donors' gifts. Moreover, the tax treatment of the entity holding the funds will also be relevant, so outcomes such as tax exemption may actually be linked to donation decisions rather than independent of them.

Previous work suggests there may be a partial crowding-out effect, with donors decreasing their donations if they will be matched (Lideikyte Huber 2020). However, warm-glow givers, as identified by a crowding-out task, increased their donations when matched and were more responsive to matching incentives than rebates (Gandullia 2019). One interesting possibility is whether conflicting previous findings are due to different motivations of participants. Another important question is whether matching is more effective if donors feel more responsible for the full, matched amount, perhaps if it is clear that matching only occurred because they personally gave. 


\section{Conclusion}

In this chapter, I have provided an overview of the research from psychology and neuroscience on different motivations for prosocial behaviour and philanthropy that may be most relevant to tax incentives. Specifically, I first outlined the distinction between altruistic and strategic motivations for prosocial decisions. These motivations differ in whether there is an extrinsic benefit to being generous or not and so correspond to the distinction between tax incentives to the donor or to the charity. A key finding is that altruistic and strategic decisions were associated with overlapping activity in the areas of the brain that compute the value of different options, but there were also neural differences between these motivations. The second distinction I described was between pure and impure, or outcome and action-oriented, altruism. The key aspect here is whether participants value outcomes for others independently of being responsible for them, or whether they only get value from the act of personally giving. This aligns with tax incentives that are independent of or linked to individuals' donation decisions, such as tax exemptions or matching grants, respectively. Results from the studies described show evidence for both of these motivations but suggest feeling responsible for helping others, warm glow, is an important factor.

In addition to insight on how to maximise the effectiveness of tax incentives in promoting philanthropy, evidence that people experience warm glow from giving may reveal an overlooked component in calculating the utility of tax incentives. Perhaps encouraging philanthropy through tax incentives also has psychological benefits for donors (Sellen 2021). There is evidence that being altruistic enhances wellbeing (Dunn et al. 2008), with a recent meta-analysis suggesting a small to medium effect of being prosocial on happiness and no evidence of publication bias (Curry et al. 2018). Interestingly, recent evidence suggests that people adapt to the warm glow of giving more slowly than to the good feeling of receiving money (O'Brien and Kassirer 2019). Prosocial behaviours have also been linked to improved physical health outcomes (Crocker et al. 2017), decreased mortality (Konrath et al. 2012), and improved relationships (Crocker and Canevello 2008). While there are many potential mechanisms for these benefits, it is possible that promoting philanthropy through effective tax incentives can create positive social outcomes for both donors and beneficiaries.

\section{References}

Adamus, M., 2017. Reasons for doing good: Behavioural explanations of prosociality in economics. Economics and Sociology, 10 (1), 122-134.

Adena, M., 2021. How can we improve tax incentives for charitable giving? Lessons from field experiments in fundraising. In: Handbook of Taxation and Philanthropy. London and New York: Routledge.

Andreoni, J., 1989. Giving with impure altruism: Applications to charity and ricardian equivalence. Journal of Political Economy, 97 (6), 1447.

Andreoni, J., 1990. Impure altruism and donations to public goods: A theory of warm-glow giving. The Economic Journal, 100 (401), 464-477.

Bartra, O., McGuire, J.T., and Kable, J.W., 2013. The valuation system: A coordinate-based meta-analysis of BOLD fMRI experiments examining neural correlates of subjective value. NeuroImage, 76 (76), 412-427.

Bekkers, R., and Wiepking, P., 2010. A literature review of empirical studies of philanthropy: Eight mechanisms that drive charitable giving. Nonprofit and Voluntary Sector Quarterly.

Berg, J., Dickhaut, J., and McCabe, K., 1995. Trust, reciprocity, and social history. Games and Economic Behavior, 10 (1), 122-142.

Bowman, W., 2006. Should donors care about overhead costs? Do they care? Nonprofit and Voluntary Sector Quarterly, 35 (2), 288-310. 


\section{Aligning tax incentives with motivations}

Breeze, B., 2013. How donors choose charities: The role of personal taste and experiences in giving decisions. Voluntary Sector Review, 4 (2), 165-183.

Camerer, C.F., 2003. Behavioural studies of strategic thinking in games. Trends in Cognitive Sciences, 7 (5), 225-231.

Camerer, C.F., and Fehr, E., 2003. Measuring social norms and preferences using experimental games. Foundations of Human Sociality. Economic Experiments and Ethnographic Evidence from Fifteen Small-Scale Societies (1214), 1-40.

Capraro, V., and Rand, D.G., 2017. Do the right thing: Experimental evidence that preferences for moral behavior, rather than equity or efficiency per se, drive human prosociality. Ssrn, 13 (1), 1-24.

Caviola, L., Faulmüllert, N., Everett, Jim, A.C.C., Savulescu, J., Kahane, G., Faulmüller, N., Everett, Jim, A.C.C., and Savulescu, J., 2014. The evaluability bias in charitable giving: Saving administration costs or saving lives? Judgment and Decision Making, 9 (4), 303-315.

Charities Aid Foundation, 2019. UK Giving 2019. London, UK: Charities Aid Foundation.

Crocker, J., and Canevello, A., 2008. Creating and undermining social support in communal relationships: The role of compassionate and self-image goals. Journal of Personality and Social Psychology, 95 (3), $555-575$.

Crocker, J., Canevello, A., and Brown, A.A., 2017. Social motivation: Costs and benefits of selfishness and otherishness. Annual Review of Psychology, 68 (1), annurev-psych-010416-044145.

Crockett, M.J., Kurth-Nelson, Z., Siegel, J.Z., Dayan, P., and Dolan, R.J., 2014. Harm to others outweighs harm to self in moral decision making. Proceedings of the National Academy of Sciences, 111 (48), 17320-17325.

Croxson, P.L., Walton, M.E., O’Reilly, J.X., Behrens, T.E.J., and Rushworth, M.F.S., 2009. Effort-based cost-benefit valuation and the human brain. Journal of Neuroscience, 29 (14), 4531-4541.

Curry, O.S., Rowland, L.A., Van Lissa, C.J., Zlotowitz, S., McAlaney, J., and Whitehouse, H., 2018. Happy to help? A systematic review and meta-analysis of the effects of performing acts of kindness on the well-being of the actor. Journal of Experimental Social Psychology, 76 (May 2017), 320-329.

Cutler et al. 2021. https://doi.org/10.1038/s41467-021-24576-w

Cutler, J., and Campbell-Meiklejohn, D., 2019. A comparative fMRI meta-analysis of altruistic and strategic decisions to give. NeuroImage, 184 (January 2019), 227-241.

Davis, D.D., Millner, E.L., and Reilly, R.J., 2005. Subsidy schemes and charitable contributions: A closer look. Experimental Economics, 8 (2), 85-106.

Dickert, S., Västfjäll, D., Kleber, J., and Slovic, P., 2012. Valuations of human lives: Normative expectations and psychological mechanisms of (ir)rationality. Synthese, 1-11.

Drevets, W.C., Savitz, J., and Trimble, M., 2008. The subgenual anterior cingulate cortex in mood disorders. CNS Spectrums, 13 (8), 663-681.

Dunn, E.W., Aknin, L.B., and Norton, M.I., 2008. Spending money on others promotes happiness. Science, 319 (5870), 1687-1688.

Eckel, C.C., and Grossman, P.J., 2003. Rebate versus matching: Does how we subsidize charitable contributions matter? Journal of Public Economics, 87 (3-4), 681-701.

Eckel, C.C., and Grossman, P.J., 2006. Do donors care about subsidy type? An experimental study. In: R. Mark Isaac and D.D. Davis, eds. Experiments Investigating Fundraising and Charitable Contributors. Bingley, UK: Emerald Group Publishing Limited, 157-175.

Engel, C., 2011. Dictator games: A meta study. Experimental Economics, 14 (4), 583-610.

Erlandsson, A., Jungstrand, A., and Västfjäll, D., 2016. Anticipated guilt for not helping and anticipated warm glow for helping are differently impacted by personal responsibility to help. Frontiers in Psychology, 7 (September), 1-19.

Everett, J. A. C., Faber, N.S., and Crockett, M.J., 2015. Preferences and beliefs in ingroup favoritism. Frontiers in Behavioral Neuroscience, 9 (February), 1-21.

FeldmanHall, O., Dalgleish, T., Evans, D., and Mobbs, D., 2015. Empathic concern drives costly altruism. NeuroImage, 105, 347-356.

FeldmanHall, O., Mobbs, D., Evans, D., Hiscox, L., Navrady, L., and Dalgleish, T., 2012. What we say and what we do: The relationship between real and hypothetical moral choices. Cognition, 123 (3), 434-441.

Fernandes, M.F., and Randall, D.M., 1992. The nature of social desirability response effects in ethics research. Business Ethics Quarterly, 2 (2), 183-205.

Frey, B.S., and Oberholzer-Gee, F., 1997. The cost of price incentives: An empirical analysis of motivation crowding-out. American Economic Review, 87 (4), 746-755. 
Gandullia, L., 2019. The price elasticity of warm-glow giving. Economics Letters, 182, 30-32.

Genevsky, A., Västfjäll, D., Slovic, P., and Knutson, B., 2013. Neural underpinnings of the identifiable victim effect: Affect shifts preferences for giving. The Journal of Neuroscience, 33 (43), 17188-17196.

Gęsiarz, F., and Crockett, M.J., 2015. Goal-directed, habitual and Pavlovian prosocial behavior. Frontiers in Behavioral Neuroscience, 9 (May), 1-18.

Gneezy, U., Keenan, E.A., and Gneezy, A., 2014. Avoiding overhead aversion in charity. Science, 346 (6209), 632-635.

Güth, W., Schmittberger, R., and Schwarze, B., 1982. An experimental analysis of ultimatum bargaining. Journal of Economic Behavior \& Organization, 3 (4), 367-388.

Harbaugh, W.T., Mayr, U., and Burghart, D.R., 2007. Neural responses to taxation and voluntary giving reveal motives for charitable donations. Science, 316 (5831), 1622-1625.

Hein, G., Morishima, Y., Leiberg, S., Sul, S., and Fehr, E., 2016. The brains functional network architecture reveals human motives. Science, 351 (6277), 1074-1078.

Kahneman, D., Knetsch, J.L., and Thaler, R.H., 1986. Fairness and the assumptions of economics. The Journal of Business, 59 (S4), S285-S285.

Konrath, S., Fuhrel-Forbis, A., Lou, A., and Brown, S., 2012. Motives for volunteering are associated with mortality risk in older adults. Health Psychology, 31 (1), 87-96.

Konrath, S., and Handy, F., 2018. The development and validation of the motives to donate scale. Nonprofit and Voluntary Sector Quarterly, 47 (2), 347-375.

Kuss, K., Falk, A., Trautner, P., Elger, C.E., Weber, B., and Fliessbach, K., 2013. A reward prediction error for charitable donations reveals outcome orientation of donators. Social Cognitive and Affective Neuroscience, 8 (2), 216-223.

Levy, D.J., and Glimcher, P.W., 2012. The root of all value: A neural common currency for choice. Current Opinion in Neurobiology, 22 (6), 1027-1038.

Lideikyte Huber, G., 2020. Tax incentives for charitable giving as a policy instrument: Theoretical discussion and latest economic research. World Tax Journal, 12 (3).

Lockwood, P.L., Apps, M.A.J., Valton, V., Viding, E., and Roiser, J.P., 2016. Neurocomputational mechanisms of prosocial learning and links to empathy. Proceedings of the National Academy of Sciences, 113 (35), 201603198.

Lockwood, P.L., Hamonet, M., Zhang, S.H., Ratnavel, A., Salmony, F.U., Husain, M., and Apps, M.A.J., 2017. Prosocial apathy for helping others when effort is required. Nature Human Behaviour, 1 (7), 1-10.

Mobbs, D., Yu, R., Meyer, M., Passamonti, L., Seymour, B., Calder, A.J., Schweizer, S., Frith, C.D., and Dalgleish, T., 2009. A key role for similarity in vicarious reward. Science, 324 (5929), 900.

Moll, J., Krueger, F., Zahn, R., Pardini, M., de Oliveira-Souza, R., and Grafman, J., 2006. Human frontomesolimbic networks guide decisions about charitable donation. Proceedings of the National Academy of Sciences of the United States of America, 103 (42), 15623-15628.

Niemi, L., Wasserman, E., and Young, L., 2018. The behavioral and neural signatures of distinct conceptions of fairness. Social Neuroscience, 13 (4), 399-415.

O’Brien, E., and Kassirer, S., 2019. People are slow to adapt to the warm glow of giving. Psychological Science, 30 (2), 193-204.

Ottoni-Wilhelm, M., Vesterlund, L., and Xie, H., 2017. Why do people give? Testing pure and impure altruism. American Economic Review, 107 (11), 3617-3633.

Peng, H.-C., and Liu, W.-J., 2020. Crowding-out (-in) effects of subsidy schemes on individual donations: An experimental study. Judgment and Decision Making, 7.

Peters, J., and Büchel, C., 2010. Neural representations of subjective reward value. Behavioural Brain Research, 213 (2), 135-141.

Pulcu, E., Zahn, R., Moll, J., Trotter, P.D., Thomas, E.J., Juhasz, G., Deakin, J.F.W., Anderson, I.M., Sahakian, B.J., and Elliott, R., 2014. Enhanced subgenual cingulate response to altruistic decisions in remitted major depressive disorder. NeuroImage: Clinical, 4, 701-710.

Rangel, A., Camerer, C.F., and Montague, P.R., 2008. Neuroeconomics: The neurobiology of valuebased decision-making. Nature Reviews. Neuroscience, 9 (7), 545-556.

Rapoport, A., and Chammah, A.M., 1965. Prisoner's Dilemma: A Study in Conflict and Cooperation. Ann Arbor, MI: University of Michigan Press.

Rilling, J.K., Gutman, D.A., Zeh, T.R., Pagnoni, G., Berns, G.S., and Kilts, C.D., 2002. A neural basis for social cooperation. Neuron, 35 (2), 395-405.

Scharf, K., 2014. Impure prosocial motivation in charity provision: Warm-glow charities and implications for public funding. Journal of Public Economics, 114, 50-57. 
Sellen, C., 2021. Philanthropy as a self-taxation mechanism with happy outcomes: Crafting a new public discourse. In: Handbook of Taxation and Philanthropy. London and New York: Routledge.

Slovic, P., Zionts, D., Woods, A.K., Goodman, R., Jinks, D., Slovic, P., Zionts, D., Woods, A.K., Goodman, R., and Jinks, D., 2011. Psychic numbing and mass atrocity. The Behavioral Foundations of Policy (11), 11-56.

Spaans, J.P., Peters, S., and Crone, E.A., 2019. Neural reward-related reactions to monetary gains for self and charity. Cognitive, Affective and Behavioral Neuroscience, 19, 845-858.

Steinberg, R., 2021. The design of tax incentives for giving. In: Handbook of Taxation and Philanthropy. London and New York: Routledge.

Ugazio, G., Bernardic, U., Lebreton, M., Lideikyte Huber, G., and Peter, H., 2021. When and how do tax incentives promote prosocial behavior and charitable giving? In: Handbook of Taxation and Philanthropy. London and New York: Routledge.

Van Iwaarden, J., Van Der Wiele, T., Williams, R., and Moxham, C., 2009. Charities: How important is performance to donors? International Journal of Quality \& Reliability Management, 26 (1), 5-22.

Västfjäll, D., Slovic, P., and Mayorga, M., 2015. Pseudoinefficacy: negative feelings from children who cannot be helped reduce warm glow for children who can be helped. Frontiers in Psychology, 6 (May), 616.

Wiech, K., Kahane, G., Shackel, N., Farias, M., Savulescu, J., and Tracey, I., 2013. Cold or calculating? Reduced activity in the subgenual cingulate cortex reflects decreased emotional aversion to harming in counterintuitive utilitarian judgment. Cognition, 126 (3), 364-372.

Wit, A. de, and Bekkers, R.H.F.P., 2017. Government support and charitable donations: A meta-analysis of the crowding-out hypothesis. Journal of Public Administration Research and Theory, 27 (2), 301-319.

Zheng, H., and Zhu, L., 2013. Neural mechanism of proposer's decision-making in the ultimatum and dictator games. Neural Regeneration Research, 8 (4), 357-362. 